\title{
RECENT ADVANCES IN PHYSICAL MEDICINE
}

\author{
SHELBY G. GAMBLE, \\ Department of Medicine, The Ohio State University
}

The field of physical medicine is expanding very rapidly and with such development is demonstrating its value in a broad and neglected phase of medicine as practiced today.

The Council on Physical Medicine of the American Medical Association defines physical medicine as including the employment of the physical and other effective properties of light, heat, cold, water, electricity, massage, manipulation, exercises and mechanical devices for physical and occupational therapy in the diagnosis and treatment of disease.

Physical Medicine is developing and progressing into three major fields: (1) physical therapy and the employment of physical agents in diagnosis, (2) occupational therapy with the usual arts and crafts plus the wider field of pre-vocational, avocational, and vocational pursuits, and (3) reconditioning of the convalescent patient which includes not only physical training but also the provision of educational and recreational programs as developed by our military services during this past world war to utilize the period between definite care and ability to return to productive work; thus shortening convalescence and obtaining maximal functional recovery.

In 1944 the Baruch Committee on Physical Medicine was initiated by the grant of Bernard M. Baruch to advance and encourage research, teaching and training in the field of physical medicine. The general research and training projects were formulated as follows:

(1) To develop both medical and technical teachers of physical medicine in the basic sciences and clinical aspects of physical medicine.

(2) To investigate the problems of hydrology, climatology and spa therapy.

(3) To study the prevention and manipulative aspects of the structural mechanics of the human body.

(4) To study and develop electronics and other physical agents because of their increasing importance in physical equipment which could be employed in research as well as in clinical application of physical medicine.

(5) To promote special clinical investigation of the psychologic and psychiatric aspects of physical medicine. 
During the past year, grants were made to a number of medical schools and Dr. Frank H. Krusen, medical director of the Baruch Committee, has summarized the projects at the specific institutions as follows:

(1) Columbia University, College of Physicians and Surgeons-Research projects dealing with insulin therapy in combination with fever therapy produced by physical means; studies of electric shock therapy; the effect of temperature on hemorrhage, fluid, and electrolyte balance; distribution of volume of blood, and metabolic disturbances resulting from circulatory changes; basic problems of circulation in small vessels and capillaries; the use of radioactive isotropes in circulation investigations.

(2) Medical College of Virginia - Study of birefringence of mammalian muscles; changes in muscle proteins during atrophy; use of electrical stimulation, massage or baths to overcome atrophy.

(3) Massachusetts Institute of Technology-Investigation of the dielectric properties of muscles and tissues in high frequency fields and nerve impulses by electronic methods.

(4) Harvard University-Study of biochemical factors relating to fatigue and the psychiatric aspects of fatigue in psychoneurotic patients.

(5) University of Southern California-The evaluation of compensatory action in muscles or muscle groups; the use of soft tissue $\mathrm{x}$-rays and metal pin implants to study muscle movement; the determination of electrical potentials in muscular contractions; the interruption of neuromuscular pathways by pressure, nerve section and chemicals; the effects of internal environment on regeneration of neuromuscular pathways and return of function.

(6) University of Iowa-Research in the use of thermogenic agents on deep tissue heating, and the effects on circulation of short wave diathermy in animal experiments.

(7) Marquette University-The effects of temperature changes on the neuromuscular apparatus with special reference to thermal shock.

(8) Washington University-Research program on body mechanics.

Laboratory research in electrodiagnosis, electromyography, and low frequency muscle stimulation has been a prominent investigative field.

In studies on peripheral nerve lesions, electrodiagnosis by means of a progressive current of long duration has shown great prognostic importance. A progressive current is one which increases with time and in peripheral nerve lesions, there is a progressive diminution in threshold amperage until the period of denervation is reached. With recovery, there is a rise in threshold amperage. These electrical signs of recovery precede clinical evidence of motor and sensory recovery often by months.

In a like manner, electromyography is of diagnostic aid in similar peripheral nerve lesions. No electrical activity can be recorded from normal relaxed voluntary muscle, although it is always present when there is action in muscle tissue. In practically denervated muscles, fibrillation action potentials can be obtained. During re-innervation, fibrillation action potentials decrease. In detecting small degrees of nerve interruption, electromyography is of particular value. It also helps in placing the level and extent of lower motor neuron lesions since the amount of denervation can be assessed. Thus work in electrophysiology and electropathology has resulted in the recording by suitable needle electrodes, the action potentials of muscles. To date such methods are chiefly used in laboratory studies but a definite clinical use is in the making.

The relation of Physical Medicine to Psychosomatic Medicine has been emphasized in the use of electric shock therapy in the various psychoses. Electric shock is the most easily administered shock therapy and the results are comparable to those of insulin and metrazol. As in other forms of shock therapy, only the existing mental state is altered. There is no change in the prepsychotic personality and other forms of psychotherapy are essential. 
The combination of physical and drug therapy in the forms of fever-chemotherapy and of ion transfer has developed further.

Studies have been continued in the use of artificial fever and chemotherapy in early syphilis in the hope to obviate the necessity of long courses of either chemotherapy or of fever-chemotherapy. Valuable data has been obtained on such combinations during this past World War.

Ion transfer with histamine and novocain has been used extensively in recent years. Irritation of the skin and underlying parts has been used more or less successfully in the treatment of aches and pains due to soft tissue involvement. Pronounced analgesic action is probable directly due to improved circulation which relieves tension in subfascial spaces and removes toxic products. Histamine ion transfer is one of the simplest and most effective counterirritant measures available. In cases of painful limited joint motion, novocain ion transfer is very effective with complete relief of symptoms plus surface analgesia for three to four hours.

Continued studies using hypotheramy further corroborated its uses for surgical anesthesia, preservation of poorly nourished tissues, treatment of infection and shock, and treatment of burns. Preliminary observations on selective destruction of superficial tumors by temporary local asphyxia using carbon dioxide ice have proven the feasibility of this method.

Ultraviolet irradiation plus the use of fluorescein has been used with success in determining the viability of strangulated intestine as well as in the establishment of diagnosis and prognosis in peripheral vascular diseases. When fluorescein is injected intravenously, it can be made visible by a beam of ultraviolet radiation on reaching any area of exposed skin or mucous membrane by the blood stream. In cases of damaged bowel, the presence of fluorescence has been shown to be sufficient evidence of viability. The postoperative course and pathologic sections have borne out the prognosis based on this method and so has removed the usual uncertainty incidental to such cases.

For years there has been a need for a means of estimating heat radiation in clinical practice. Recently there has been developed an experimental instrument, a thermoradiometer, which can be placed in the patient's skin and directly measure the radiation flux. It is hoped that a simple clinical recording instrument that will allow more accurate estimate of administering heat radiation will be an outgrowth of these experiments.

Laboratory experimentation with microwaves and supersonics as well as with the cyclotron and atomic energy have indicated that it is within the range of definite possibility that the therapeutic use of these powerful new forms of physical energy may bring far-reaching developments. Radioactive sodium as prepared by means of the cyclotron has already been used as a tracer substance in the blood in the study of patients with peripheral vascular disease. Thus the past few years have shown progressive advances of sound large scale developments in physical medicine.

\section{BIBLIOGRAPHY}

1. Allen, F. M., Safford, F. K., Jr., and Crossman, L. W. Freezing Treatment of Tumors. Arch. of Phys. Med., 26: 499-501, Aug., 1945.

2. Barer, A. P., and Fowler, W. M. Effects of Uitraviolet Irradiation on Blood Hemoglobin. J. Lab. \& Clin. Med., 30: 600-603, July, 1945.

3. Crossman, L. W., and Allen, F. M. Principles of Surgical and Therapeutic Refrigeration. S. Clin. North Am., 25: 361-370, April, 1945.

4. Evans, D. S., and Mendelssohn, K. Estimation of Heat Radiation in Clinical Practice. British Med. J., 2: 811-814, Dec. 23, 1944.

4. Hatfield, C. A., Buyers, R. A., and Walking, A. A. Fluorescein-Its Use in Determining the Viability of Strangulated Intestine. Surg. Gyn. \& Obst., 81: 532 (Nov.) 1945.

6. Kendell, H. W., Rose, D. L., Miller, Elsie, and Simpson, W. M. Artificial Fever and Chemotherapy in Early Syphilis. Arch. of Int. Med., 26: No. 2: 76-85, Feb., 1945.

7. Kovacs, Richard. The 1945 Year Book of Physical Medicine. The Year Book Publishers, Chicago, Ill. 
8. Kross, Isidor. Low Temperature Therapy for Preservation of Limbs. J. A.M.A., 128 19-20, May 5, 1945.

9. Krusen, F. H. The Expanding Field of Physical Medicine. Proc. Staff Meet., Mayo Clinic, 20: 497 (Dec. 26), 1945.

10. Lange, K., and Boyd, L. J. Use of Fluorescein Method in Establishment of Diagnosis and Prognosis of Peripheral Vascular Disease. Arch. Int. Med., 74: 184 (Sept.), 1944.

11. Loewy, F. E. Histamine Ion Transfer in General and Industrial Practice. Brit. J. Phys. Med., 8: 115-116, July and August, 1945.

12. Piersol, George M., M.D. Functions of a Center for Instruction and Research in Physical Medicine. Arch. of Phys. Med., 26: 133-139, Mar., 1945.

13. Pollock, L. J., Golseth, J. G., Arieff, A. J., and Mayfield, F. Electrodiagnosis by Progressive Currents of Long Duration: Studies on Peripheral Nerve Injuries in Man. Surg., Gyn. \& Obst., 81: 192-200, Aug., 1945.

14. Quimby, E. H., and Smith, B. C. Tracer Studies with Radioactive Sodium in Patients with Peripheral Vascular Disease. Science, 100: No. 2591, 175-177, (Aug. 25), 1944.

15. Ruskin, S. H. Electric Shock Therapy of Psychoses. Arch. Phys. Med., Vol. 26, No. 3, 168-172, March, 1945.

16. Snow, W. B., and Kraus, H. Novocain Ion Transfer for Painful Limitation of Motion. Mil. Surgeon, 95: 361-362, Nov., 1944.

17. Weddell, G. Electromyography. N Times, N. Y., 73: 37-39, Feb., 1945. 